\title{
Management of Liquid Waste in a Clinical Laboratory
}

\author{
C. Nagaraj* \\ Department of Microbiology, PES Institute of Medical Sciences and Research, \\ Kuppam-517425, Chittoor District, Andhra Pradesh, India \\ *Corresponding author
}

\begin{tabular}{|l|}
\hline K e y w o r d s \\
$\begin{array}{l}\text { Sodium hypochlorite, } \\
\text { Body fluid disposal, } \\
\text { Double bucket system, } \\
\text { Liquid biomedical waste } \\
\text { management, Clinical } \\
\text { Laboratory waste } \\
\text { management, Hospital } \\
\text { infection control practices }\end{array}$ \\
\hline Article Info \\
\hline $\begin{array}{l}\text { Accepted: } \\
\text { 22 July } 2018 \\
\text { Available Online: } \\
\text { 10 August } 2018\end{array}$ \\
\hline
\end{tabular}

\section{Introduction}

Lots of literature is available regarding the methods of biomedical waste disposal but only a few describe about the liquid waste. Appropriate Biomedical waste management is mandatory, legal and traceable (Government of India BMW rule - 2018). Liquid waste is usually neglected leading to inadvertent release of the infected liquid waste into the public drainage system. This may sometime
Clinical Laboratory produces large quantities of liquid infectious waste in the form of body fluids including blood. Biomedical waste management generally covers the solid waste generated in the Health care set up. Liquid infected waste management in a hospital is mainly addressed in the form of Sewage treatment plant (STP) or Effluent treatment plant (ETP) which is made mandatory for hospitals. Construction of these facilities involves lot of financial expenditure. Small facilities may not be able to afford to construct a STP or ETP in their facility. There may be place and / or budgetary constraints. Current study addresses the small-scale health care facility like a standalone Clinical Laboratory wherein the liquid waste could be let into the public drainage system after pre treatment to remove infectious agents. This article highlights the use of easily available and affordable material for the construction of a disinfection system in a facility. After disinfection of the liquid waste, it could be safely discarded into the sewage system without fear of releasing toxic or infectious material into the public drainage system. It also suggests an alternative backup system if the primary step of disinfection is missed out wherein the wash basin is connected to a large container where the discarded liquid waste collects and before it is let into the public drain, it is mixed with $1 \%$ Sodium Hypochlorite and retained for a contact period of 20 minutes before the outlet valve is opened to drain out the disinfected liquid waste. This is cost effective, affordable and easy to use liquid waste management for any small and medium Clinical laboratory or small clinical setup. 
drugs could also be discarded into this liquid handling system and treated with appropriate chemicals before they are disposed.

This study deals with a construction of a simple liquid waste management system for a Clinical Laboratory.

\section{Materials and Methods}

Double buckets are used to decontaminate the liquid waste from a Clinical laboratory before it is discarded into the Municipal Sewage system. Liquid waste with its containers is handled in a safe manner thereby preventing exposure of the Laboratory staff to the infectious or hazardous waste.

\section{Construction of the Double bucket system}

The materials required include a medium sized (16 liter capacity) plastic bucket with a lid and a paper thrash bin (second bucket) which easily goes into the outer bucket as seen in Figure 1a. With lots of openings, the liquid waste is in continuous contact within the bucket and trash. Four to five big sized holes $(1 \mathrm{~cm}$. each) are drilled into the bottom of the paper trash so that when it is lifted up, the liquid within the trash easily gets drained into the outer bucket. With this, the double bucket system is ready for use.

Liquid waste generated in the laboratory could be blood, body fluids, sputum, vomit, urine of patients. Reagents which come in contact with the blood and body fluids get contaminated and could be infectious to the laboratory staff. The staff wearing personnel protective equipments (PPE), discard the liquid waste along with the specimen containers after opening the lid so that the disinfectant directly comes in contact with the infectious material and decontaminate the infectious waste and the container making it safe to discard. The required quantity of disinfectant can be calculated depending on the quantity of the waste that is to be discarded. A fresh $1 \%$ Sodium hypochlorite (as an example) is prepared and poured into the inner bucket with the waste required to be disinfected. The lid of the outer bucket is closed for at least 20 minutes of contact time. The lid is then opened. The inner bucket is lifted up to drain the liquid disinfected contents to drain into the outer bucket. An appropriate biomedical liner (as per biomedical waste segregation rule) is clung on to the mouth of inner bucket which is then tilted and the containers transferred to the appropriate biomedical waste segregation bag for handing over to the Biomedical segregation and holding area for final disposal. The disinfected liquid in the outer bucket is then poured out in a separate commode meant for liquid waste disposal and flushed.

\section{Construction of a backup system}

Backup system is made available to see that no waste goes out without decontamination if liquid waste does not get the primary disinfection in the double bucket system. A laboratory wash basin is converted to decontaminate liquid waste (Fig. 2). Outlet of the wash basin is connected to a big plastic container with lid. The outlet of this container opens into the drain. A valve is provided to regulate the flow of liquid waste and the Sodium hypochlorite solution can be directly poured into the wash basin so that it reacts with the liquid waste discarded into the container with the valve closed so that the contents do not flow into the drain.

Now the contents are allowed to stand for 20 minutes after which, the valve is opened so that the disinfected liquid waste can now flow into the drain. However, in this backup system, the specimen container has to be discarded separately and disinfected since they are not disinfected in the process. 


\section{Results and Discussion}

World Health Organization, in its publication "Module 23 - Management of Health care wastewater" (2008) classifies health care liquid waste into three types:

Blackwater (sewage) is heavily polluted wastewater containing high concentrations of:

Faecal matter and urine

Food residues

Toxic chemicals

Greywater (sullage) is low polluted wastewater with residues from:

Washing, bathing, laboratory processes, laundry, or technical processes such as cooling water or the rinsing of X-ray films
Stormwater is technically not wastewater but consists of rainfall collected on hospital roofs, grounds, and paved surfaces

It may seep into groundwater, or be used for irrigation of hospital grounds or toilet flushing.

It also classifies wastewater contaminants:

Important chemicals in hospital wastewater include anesthetics, disinfectants (formaldehyde, glutaraldehyde), chemicals from laboratory activities, photochemical solutions (hydroquinone), and X-ray contrast media containing absorbable organohalogen compounds (AOX)

Mercury from dental amalgams or lab chemicals

Fig.1 Construction and use of double bucket for decontamination of liquid waste (Blood vacutainers used here as an example)

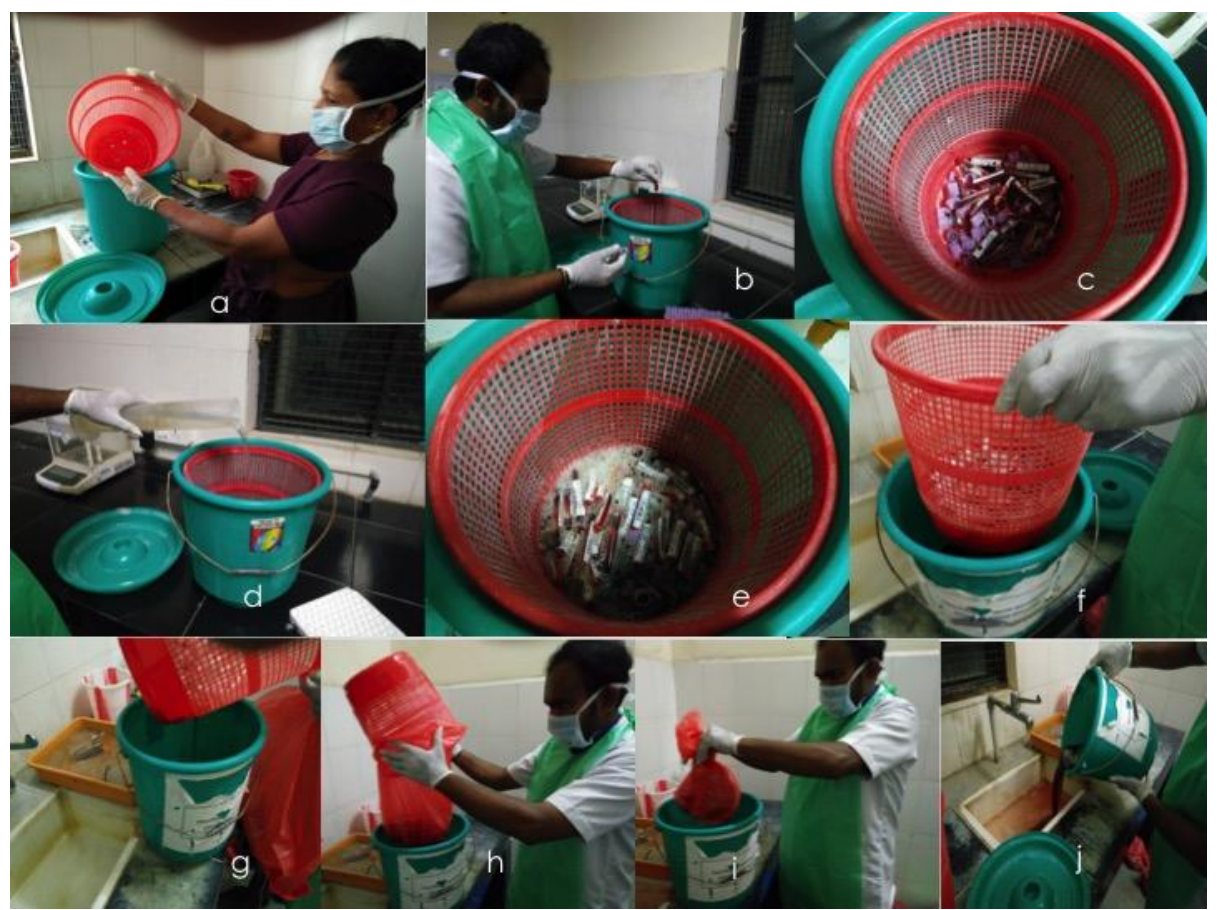

Legend: a. Construction of a double bucket; b. Pouring the samples into the double bucket; $c$. Open vacutainers discarded into the double bucket; d. Pouring the required quantity of $1 \%$ Sodium hypochlorite; e. Soaking the vacutainers along with blood for 20 min.; f, g. Lifting the inner bucket and draining the liquid treated waste; $\mathrm{h}$. Transferring the treated vacutainers into the red liner bag; $i$. Tying the bag with treated vacutainers; $j$. Pouring the treated liquid waste into the drain. 
Fig.2 Backup system for decontamination of liquid waste

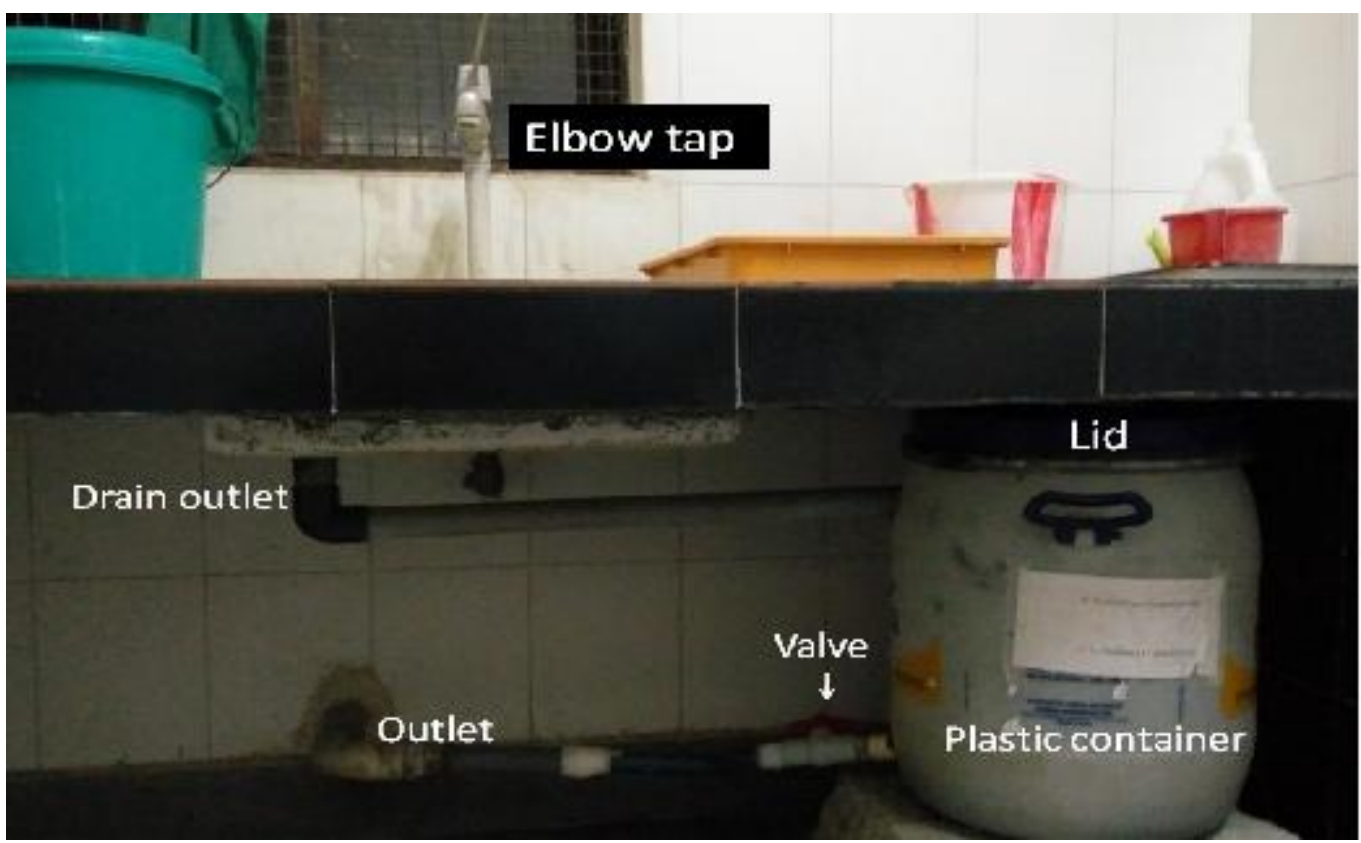

Excessive nutrients and nitrates

Pharmaceuticals, including antibiotics

Radioactive wastes

Infectious agents, including bacteria, viruses and parasites

Chitnis et al., (2005) in their review article discuss the need for audit of the BMW required for planning proper strategies.

The audit in their laboratory revealed $8 \mathrm{kgs}$ anatomical waste, $600 \mathrm{kgs}$ microbiology waste, $220 \mathrm{kgs}$ waste sharps, $15 \mathrm{kgs}$ soiled waste, $111 \mathrm{kgs}$ solid waste, 480 litres liquid waste along with 33000 litres per month liquid waste generated from labware washing and laboratory cleaning and 162 litres of chemical waste per month.

Finally they conclude that the liquid waste management needs more attention and effluent treatment facility to be considered seriously for hospitals in general.
Apart from these references, there are no other recommendations regarding the liquid waste management in a hospital setup or for a clinical laboratory.

However, this article deals mainly with the development of a suitable and safe method for liquid waste management for a small standalone clinical laboratory or a small hospital. The materials used are affordable. It can be fabricated by the facility themselves with the easily available materials from the market.

They are quite safe to use and can be maintained by any person not requiring high level of training. Other disinfectant solution (Calcium hydroxide, calcium oxide) or powder (bleaching powder or lime) can also be used in this double bucket system.

\section{Acknowledgement}

Author is thankful to the management for all the encouragement and to the staff of Department of Microbiology, PESIMSR, Kuppam, Andhra Pradesh for their support. 


\section{References}

BMW Rule 2018 (2018) [Published in the Gazette of India, Extraordinary [PART II-SEC. 3 (i)] pp $1-12$.

Chitnis, V., et al., (2005) Biomedical Waste in Laboratory Medicine: Audit and management. Indian Journal of Medical Microbiology, 23 (1):6-13

World Health Organization (2008). In: "Module 23 - Management of Health care wastewater" Global Health-care Waste Project jointly sponsored by UNDP, the Global Environment Facility, WHO, Health-care.

\section{How to cite this article:}

Nagaraj, C. 2018. Management of Liquid Waste in a Clinical Laboratory. Int.J.Curr.Microbiol.App.Sci. 7(08): 4024-4028. doi: https://doi.org/10.20546/ijcmas.2018.708.416 